\title{
Deontological violations of community pharmacies in Turkey
}

\author{
Bülent Kıran* (D), Elif Gizem Karaca (D) \\ Department of Pharmacy Management, Faculty of Pharmacy, Ege University, 35100, Izmir, Turkey
}

ORCID IDs of the authors: B.K. 0000-0001-8734-6095; E.G.K. 0000-0001-9432-7888.

Cite this article as: Kıran B, Karaca EG (2019). Deontological violations of community pharmacies in Turkey. Istanbul J Pharm 49 (1): 20-24.

\begin{abstract}
Deontological violations are important in terms of reputation of public health, pharmacy profession, and protection of public finance. The aim of this study is to determine types and prevalence of deontological crimes reflected in records of High Honor Court (HHC) in Turkish Pharmacists' Association (TPA), to develop proposals on corrective and preventive occupational policies. Crime types in disciplinary files were classified according to classification method of deontological crimes in 3-groups, and results were evaluated by frequency and percentage distributions.

In the study, 32 deontological crime types and 112 criminal cases were detected. Accordingly, it was found that deontological crimes due to competition are in the first rank with 51 cases, TPA, Drug-Pharmacy Legislation violations in the second with 50 cases and Social Security Institution protocol provisions violations in the last rank with 11 cases, and in all types of crime, "collusion" is in the first rank $(30.4 \%)$.It is thought that "collusion" crime being in the first rank increasing its share from $18.6 \%$ to $30.4 \%$ in all crimes despite increasing punishments.

Persistence of crime despite punitive sanctions aggravated by recent regulations suggests that it is not possible to solve only by punitive sanctions, and it must be get to the bottom of the problem.
\end{abstract}

Keywords: Pharmacy, community pharmacies, deontological violations, deontological crimes

\section{INTRODUCTION}

Prevention of deontological violations committed in community pharmacies is important for the protection of public health, the reputation of pharmacy profession and public finance. It has been shown that these deontological violations increase during periods of liberalization policies applied in the healthcare field and economic crises (Kıran 2009; Kıran and Mandıracıoğlu 2013).

There are many laws and regulations related to pharmacy, mainly the Deontology Regulation of the Turkish Pharmacist's Association (TPA), as well as binding provisions in agreements of Social Security Institution (SSI) in order to prevent community pharmacists in Turkey to be getting involved in deontological violations. In recent years, "Regulation on the Establishment of the Collusion Evaluation Commissions and its Working Rules and Principles" issued by the Turkish Ministry of Health, Turkish Medicines and Medical Devices Agency which entered into force on 14.03.2016 is also an important legislative regulation. In Article 4/d of this Regulation; "Collusion is defined as; business activity jointly or individually by someone other than the pharmacist who appears as the owner and responsible manager of the pharmacy, whether or not he/she is in line of duty, through confidential or open, written or oral agreements as well as all such activities" (TiTCK Circular 2016).

\section{This research was presented as a poster presentation at the $12^{\text {th }}$ International Symposium on Pharmaceutical Sciences (ISOPS) in Ankara, Turkey, on June 2018.}


In addition, according to Article 48-(4) of the Regulation on Pharmacists and Pharmacies held in 2014, in case of the detection of the establishment of pharmacies opened as collusive, the license will be cancelled, and penal sanctioning have been set as these pharmacists will not be able to open a pharmacy for five years" (Official Gazette 2014). Despite these regulations that have been issued in recent years and contain severe punitive sanctions, there is little research investigating the deontological violations in Turkey.

In this context, this study was conducted in order to determine the types and prevalence of deontological violations

\section{Table 1. Grouped Distribution of High Honor Court Cases According to Types of Violation}

\begin{tabular}{lcc} 
* Violation Type of HHC Cases & & \\
2015-2017 Years & $\%$ & $\mathrm{n}$ \\
\hline $\begin{array}{l}\text { 1. Competition-Based } \\
\text { Deontological Violations }\end{array}$ & 51 & 45.6 \\
2.TPA, Drug-Pharmacy & & \\
Legislation Violations & 50 & 44.6 \\
$*$ 2.1. Collusion & $*(34)$ & $*(68)$ \\
3.SSI Protocol Provisions Violations & 11 & 9.8 \\
Total & 112 & 100 \\
$*$ Collusion & $*(34)$ & $*(30,4)$ \\
\hline
\end{tabular}

*HHC: High Honor Court

\section{Table 2. Detailed Distribution of Violations} Submitted in High Honor Court Cases (2015-2017)

\begin{tabular}{|c|c|c|}
\hline Violations & $n=112$ & $\%$ \\
\hline Operating collusive pharmacy & 34 & 30.4 \\
\hline Prescription collection and transfer & 19 & 17.0 \\
\hline $\begin{array}{l}\text { Violation of night-pharmacy, failure to } \\
\text { comply with opening and closing times }\end{array}$ & 12 & 10.7 \\
\hline Over-the-counter and wholesale drug sales & 10 & 8.9 \\
\hline Advertisement, Promotion & 3 & 2.7 \\
\hline Not taking patient share and price difference & 2 & 1.8 \\
\hline Creating a website & 2 & 1.8 \\
\hline $\begin{array}{l}\text { Over-the-counter and wholesale of controlled } \\
\text { medicines and narcotic drugs }\end{array}$ & 2 & 1.8 \\
\hline $\begin{array}{l}\text { Invoicing of drugs to the Institution, which } \\
\text { are not delivered to patients }\end{array}$ & 2 & 1.8 \\
\hline Not delivery of drugs to patients & 2 & 1.8 \\
\hline Having drugs not delivered to patients & 2 & 1.8 \\
\hline Having expired drugs & 1 & 0.9 \\
\hline $\begin{array}{l}\text { Not giving the documents requested } \\
\text { by the auditor pharmacists }\end{array}$ & 1 & 0.9 \\
\hline $\begin{array}{l}\text { Not appointing responsible manager } \\
\text { during departures over } 24 \mathrm{~h}\end{array}$ & 1 & 0.9 \\
\hline $\begin{array}{l}\text { Recording a prescription to SSI Medula system } \\
\text { to prevent drug purchase from other pharmacies }\end{array}$ & s 1 & 0.9 \\
\hline Failure to comply with cold chain rules & 1 & 0.9 \\
\hline $\begin{array}{l}\text { Having products with uncertain content } \\
\text { and manufacturer }\end{array}$ & 1 & 0.9 \\
\hline
\end{tabular}

reflected in the records of High Honor Court ( $\mathrm{HHC}$ ) in the TPA, and to develop proposals on corrective and preventive occupational policies.

\section{MATERIALS AND METHODS}

The research is cross-sectional. Crime types in disciplinary files in TPA Period-40 Working Report between 10.12.201530.09.2017 of HHC in TPA and submitted from 54 Regional Pharmacists Chamber in Turkey were classified according to classification method of deontological violations in 3-groups, and results were evaluated by frequency and percentage distributions (Kıran and Mandıracıoğlu 2013; Turkish Pharmacist's Association 2015; Turkish Pharmacist's Association 2017). Some files have been discussed more than once in the High Honor Court for various reasons. Therefore, although the total number of files is 99, it is reflected as 112 in the study report.

\section{RESULTS}

32 deontological violation types and a total of 112 deontological violation cases were detected from 54 Regional Pharmacists Chamber in Turkey submitted to High Honor Court in TPA between 2015-2017 years. These violations were classified in 3-groups according to classification method used in the first and only study on deontological violations committed in Turkey's community pharmacies (Kıran

Not covering the prescription despite the institution prescription line is available Absentee

Prescribing drugs outside patient knowledge 1

Disruptive behavior for the functioning

of chamber departments

Not giving information and documents requested by the board of directors

Invoicing of fake prescription, report, drug bar code and 2-d barcode

Establishing business relationship that does not conform to occupational ethics

Lack of illuminated and current nightpharmacy boards

Keeping drugs with impaired original package 1

Over-the-counter sale of unlicensed and illegal drugs

Having drugs without complete 2-d barcode

Improper action against the chamber president in terms of professional norms and dignity

Injection in pharmacy

Preventing the patient's access to drugs and purchase the drug from the preferred pharmacy by recording trial prescription to the Medula Provisioning System 


\section{Table 3. Distribution of deontological violations according to regional pharmacy chambers(2015-2017)}

\begin{tabular}{lcc} 
Regional Chamber of Pharmacists & $\mathrm{n}=99$ & $\%$ \\
\hline 1. İstanbul Chamber of Pharmacists & 33 & 33.3 \\
2. Ankara Chamber of Pharmacists & 16 & 16.2 \\
3. Adana Chamber of Pharmacists & 7 & 7.1 \\
4. Mersin Chamber of Pharmacists & 7 & 7.1 \\
5. Kocaeli Chamber of Pharmacists & 6 & 6.1 \\
6. Balıkesir Chamber of Pharmacists & 5 & 5.1 \\
7. Sanlıurfa Chamber of Pharmacists & 3 & 3.0 \\
8. Konya Chamber of Pharmacists & 3 & 3.0 \\
9. Izmir Chamber of Pharmacists & 3 & 3.0 \\
10. Manisa Chamber of Pharmacists & 2 & 2.0 \\
11. Bursa Chamber of Pharmacists & 2 & 2.0 \\
12. Antalya Chamber of Pharmacists & 2 & 2.0 \\
13. Erzurum Chamber of Pharmacists & 1 & 1.0 \\
14. Eskișehir Chamber of Pharmacists & 1 & 1.0 \\
15. Tekirdağ Chamber of Pharmacists & 1 & 1.0 \\
16. Isparta Chamber of Pharmacists & 1 & 1.0 \\
17. Trabzon Chamber of Pharmacists & 1 & 1.0 \\
18. Kırklareli Chamber of Pharmacists & 1 & 1.0 \\
19. Ușak Chamber of Pharmacists & 1 & 1.0 \\
20. Gaziantep Chamber of Pharmacists & 1 & 1.0 \\
21. Giresun Chamber of Pharmacists & 1 & 1.0 \\
22. Batman Chamber of Pharmacists & 1 & 1.0
\end{tabular}

and Mandıracıoğlu 2013; Turkish Pharmacist's Association 2015; Turkish Pharmacist's Association 2017).

Accordingly, it was found that "competition-based deontological violations" are in the first rank with 51 cases (45.6\%), TPA, "Drug-Pharmacy Legislation violations" in the second with 50 cases (44.6\%) and "Social Security Institution (SSI) protocol provisions violations" in the last rank with 11 cases (9.8\%). It was found that collusion evaluated under the scope of TPA, Drug-Pharmacy Legislation violations consist of $68 \%$ of the violations in this group with 34 cases and in all types of violation it is in the first rank with $30.4 \%$. Groups according to the type of violation are shown in Table 1, and the detailed distribution of all violations is shown in Table 2.

The most intensive deontological violations during 20152017 are determined in İstanbul (33.3\%), Ankara (16.2\%), Adana (7.1\%) and Mersin (7.1\%). Distributions of deontological violations for the years of 2015-2017 according to Regional Pharmacy Chambers are shown in Table 3.

During 2015-2017, disciplinary punishments given by the High Honor Court are defined as temporary prohibit from practice $(42.4 \%)$, penalty fine (21.2\%), written warning (3\%) and files returned with various reasons (33.4\%). Distribution of punishments given to violations by the High Honor Court is shown in Table 4.

Table 4. Distribution of punishments given by the High Honor Court (2015-2017)

\begin{tabular}{lcc|} 
Punishments Given To Violations By The High Honor Court & $\mathrm{n}=99$ & 21 \\
\hline Ostracized from profession for 180 days & 16 & 1.2 \\
Penalty fine for 15 times the yearly chamber contribution & 15 & 12 \\
Ostracized from profession for 3 days & 8 & 15.2 \\
Returned due to lack of evidence & 3 & 12.1 \\
Returned & 3.1 \\
Penalty fine for 10 times the yearly chamber contribution & 3.0 \\
Written warning & 3 & 3.0 \\
Returned due to finalization since it is not appealed in given time & 3 & 3.0 \\
Returned due to make decision according to the outcome of litigation & 2 & 3.0 \\
Penalty fine for 5 times the yearly chamber contribution & 2 & 2.0 \\
Waiting to be discussed after completing notification & 2 & 2.0 \\
Ostracized from profession for 5 days & 2 & 2.0 \\
Ostracized from profession for 30 days & 1 \\
Ostracized from profession for 15 days & 2.0 \\
Ostracized from profession for 20 days & 1 \\
Returned due to lack of procedure & 1 & 1.0
\end{tabular}

Table 5. Comparative Distribution of Deontological Violation Types by Years

\begin{tabular}{|c|c|c|c|c|c|c|}
\hline \multirow[b]{2}{*}{ Violation Types } & \multicolumn{2}{|c|}{$1987-2010$} & \multicolumn{2}{|c|}{ 2013-2015 } & \multicolumn{2}{|c|}{$2015-2017$} \\
\hline & $\%$ & $\mathrm{n}$ & $\%$ & $\mathrm{n}$ & $\%$ & $\mathrm{n}$ \\
\hline 1. Competition-Based Deontological Violations & 53 & 165 & 50.8 & 64 & 45.6 & 51 \\
\hline 2.TPADrug-Pharmacy Legislation Violations & 24.6 & 77 & 35.7 & 45 & 44.6 & 50 \\
\hline$* 2.1$. Collusion & 76.3 & $* 58$ & *48.7 & *22 & *68 & *34 \\
\hline 3. SSI Protocol Provisions Violations & 22.4 & 70 & 13.5 & 17 & 9.8 & 11 \\
\hline Total & 100 & 312 & 100 & 126 & 100 & 112 \\
\hline
\end{tabular}


Since the records of the last four years of the High Honor Court (2013-2015) and (2015-2017) were examined together with the first study records examined deontological violations in Turkey, it is understood that the order of prevalence of violation (case) types has not changed (Table 5).

\section{DISCUSSION AND CONCLUSION}

When compared, Turkey's first study based on long term records with 2015-2017 Report of HHC Period-40 with the Working Report of HHC for 2013-2015; it was seen that competition-based deontological violations in the first rank with 53\% decreased to 50.8\% during 2013-2015 years and to $45.6 \%$ during 2015-2017 years (Kıran and Mandıracıoğlu 2013; Turkish Pharmacist's Association 2015; Turkish Pharmacist's Association 2017). On the other hand; it was determined that TPA Drug-Pharmacy Legislation Violations with $24.6 \%$ increased to $35.7 \%$ during 2013-2015 years and this upward trend has continued during 2015-2017 years reaching up to $44.6 \%$ and one of the most important main factors in this trend was collusion violations. In addition, SSI violations with $22.4 \%$ decreased to $17 \%$ and then $9.8 \%$ within the years and it is thought that the SSI has played a role in this decrease with severe penalties imposed on community pharmacies (Kıran 2015).

The most common violation types; prescription collection and transfer (17\%), violation of night-pharmacy, failure to comply with opening and closing times (10.7\%), over-thecounter and wholesale drug sales (8.9\%), advertisement and promotion activities (2.7\%) among competition-based deontological violations, and not delivering drugs to patients and invoicing drugs to the institution (3.6\%) among SSI violations.

In TPA Drug-Pharmacy Legislation Violations; it is thoughtprovoking that "collusion" violation in the past (76.3\%) is still the most common violation (68\%) and in the first rank increasing its share from $18.6 \%$ to $30.4 \%$ in all violations despite increasing punishments (Kıran and Mandıracıoğlu 2013; Turkish Pharmacist's Association 2015; Turkish Pharmacist's Association 2017).

Persistence of violation despite punitive sanctions aggravated by recent regulations suggests that it is not possible to solve only by punitive sanctions, and it must be get to the bottom of the problem (Higuchi and Kodama 2011; Panitch and Leys 2009; Wiberg 2011).

\section{Suggestions}

It is thought that it is necessary to work together with all stakeholders for solution of economic and educational problems in pharmacy, especially for the payment of sufficient salary during the retirement of community and public pharmacists and for creation of adequate and new employment areas in all fields of public, universities, pharmaceuticals and pharmacy according to the number of beds in hospitals and the production capacity of the indus- try, other than community pharmacy for pharmacists who have graduated from more than fifty pharmacy faculties in order to prevent collusion violation that endangers community health care, causes illegal events and harms the public economy and makes unrepairable damages to the reputation of the pharmacy profession.

Ethics Committee Approval: Ege University Scientific Research and Publication Ethics Committees does not require the application of the ethics committee for the data collected from the working reports.

Informed Consent: The authors used the TPA Period-40 Working Report between 10.12.2015-30.09.2017 of HHC.

Peer-review: Externally peer-reviewed.

Author Contributions: Concept - B.K.; Design - B.K.; Supervision B.K. Resource - B.K. Materials - B.K., E.G.K.; Data Collection and/or Processing - B.K., E.G.K. Analysis and/or Interpretation - B.K., E.G.K. Literature Search - B.K., E.G.K..; Writing - B.K., E.G.K.Critical Reviews B.K.

Acknowledgements: The authors, would like to thank Turkish Pharmacists' Association for publishing the TPA Period-40 Working Report between 10.12.2015-30.09.2017 of HHC.

Conflict of Interest: The authors have no conflict of interest to declare.

Financial Disclosure: The authors declared that this study has received no financial support.

\section{REFERENCES}

Higuchi N, Kodama Y (2011). Scheme of reeducation and administrative punishment to pharmacist, investigation commission on administrative punishment to pharmacist. Japan Pharmaceutical Association. $1^{\text {st }}$ ed, JPA Press, Tokyo. p. 127215.

- Kıran B (2009). The study of the relationship of the health policies and economic crises and deontological violations in community pharmacies in İmir city. J Fac Pharm Ankara 38: 269-283.

- Kıran B (2015). Problems Arising from Protocols of Social Security Institution with Community Pharmacists. Turkiye Klinikleri J Med Ethics Law Hist-Special Topics 1: 23-31.

- Kıran B, Mandıracıoğlu A (2013). Deontological Crimes of the Community Pharmacies in Izmir. Türkiye Klinikleri j Med Sci 33: 635-647. [CrossRef]

- Panitch L, Leys C (2009). Socialist register 2010. Morbid Symptoms: Health Under Capitalism. 1st ed, Merlin Press, London. p. 143-15.

- Official Gazette (2014). http://www.resmigazete.gov. $\mathrm{tr} / \mathrm{main}$.aspx?home=http://www.resmigazete.gov.tr/ eskiler/2014/04/20140412.htm\&main=http://www.resmigazete.gov.tr/eskiler/2014/04/20140412.htm Accessed on: 15.03 .2018

- TiTCK Circular (2016). https://www.titck.gov.tr/PortalAdmin/ Uploads/UnitPageAttachment/uFkZPI7P.pdf Accessed on: 15.03.2018

- Turkish Pharmacist's Association (2015) Period-39 Working Report, Section 7, Mattek Matbaacılık Basım Yayın Tanıtım Tic. San. Ltd. Şti. Ankara, p. 227-237. 
Istanbul J Pharm 49 (1): 20-24

- Turkish Pharmacist's Association (2017) Period-40 Working Report, Section 6 Fersa Matbaacılık Ltd. Şti. Ankara, p. 409418. [CrossRef]
Wiberg C (2011). Pharmacy and pharmacists Law, licensing and operation regulations. Minnesota Board of Pharmacy. $1^{\text {st }}$ ed, Minnesota's Bookstore, Minnesota p. 21-136. 